\title{
AC 2007-1455: USING THE AISC STEEL BUILDING CASE STUDY IN A STRUCTURAL ENGINEERING COURSE SEQUENCE
}

\section{Hector Estrada, University of the Pacific}

Dr. Hector Estrada is Professor and Chair of the Department of Civil Engineering at the University of the Pacific. He has held positions at Texas A\&M University-Kingsville and Vanderbilt University. 


\title{
Using the AISC Steel Building Case Study in a Structural Engineering Course Sequence
}

\begin{abstract}
The American Institute of Steel Construction (AISC) has made available a case study of a steel building; complete with detailed design calculations for loads and design of the structural frame. The material also includes numerous photos of the construction process, detailed plans (in AutoCAD), animations of some design concepts that are difficult to explain (such as local buckling), and a virtual three-dimensional model of the entire frame system, which can be viewed from any vantage point. The virtual 3D model also includes detailed connections. This tool has been incorporated in the structural engineering course sequence for civil and architectural engineering students. The sequence includes: statics, mechanics of materials, structural analysis, structural steel design, and a capstone design course. This paper presents the details of how the entire steel building case study has been incorporated into the teaching of the structural engineering course sequence, from statics to the capstone design course. In statics, building loads are discussed, which can be illustrated with some of the animations included in the AISC material. In mechanics of materials, connection failure animations are incorporated. The topic of loads is covered in detail in the structural analysis course, where several of the visual aids are used to illustrate difficult concepts, such as tributary area. Once the loads are established, students are asked to perform the analysis of the building frame. Design of different members of the building frame (bracing, beams, columns, connections) is covered in the structural steel design course. Finally, the entire system is covered in the capstone design course. These types of tools are very useful because they provide students with a "real world" case to study throughout their structural engineering training. Results obtained from the end of class student evaluations have not changed significantly since the introduction of the case study in the structural engineering course sequence; however, the students have made a number of positive comments regarding the use of these materials in the course evaluation surveys.
\end{abstract}

\section{Introduction}

Structural engineering is an integral part of most civil and architectural engineering programs across the United States. The National Council of Structural Engineers Associations (NCSEA) has developed a basic education curriculum to prepare a structural engineer for practice. This basic curriculum includes coursework in analysis, matrix methods, steel design, and six other areas (Barnes, 2004). NCSEA also conducted a survey of the national structural engineering curriculum and found that most institutions that responded (105 programs) offer courses in the areas specified in the basic education curriculum for a structural engineer; and although a number of programs offer the full curriculum, most programs do not require students to take the full curriculum specified to be certified as a structural engineer. However, steel design is one of the most popular areas covered at most of the institutions surveyed. 
To see specific details regarding the particular required courses in structural engineering at different institutions for architectural and civil engineering, we can study the surveys conducted by Estrada (2006) for architectural engineering and Russell and Stouffer (2005) for civil engineering. Most of the 17 architectural engineering programs in the nation require a structural engineering component to meet ABET (Accreditation Board for Engineering and Technology) accreditation curricular requirements. The survey conducted by Russell and Stouffer (2005) included results from $40 \%$ of the civil engineering programs ( 90 programs) in the nation, over half of which required at least one course in structural steel design.

Those of us who are in this 50 percentile of the programs that require structural steel design enjoy great support from the American Institute of Steel Construction (AISC), which makes available several education programs. Of the many programs that AISC offers educators of steel design, one of the best is the Web-Enhanced Teaching of Structural Steel Design toolkit, which was developed by Adolfo Matamoros and Kim Roddis at the University of Kansas with support from AISC. "The main goal of this teaching aid is to provide instructors with a tool to expose students to design of steel building elements in a realistic building context" (Roddis, 2006). This tool serves to connect classroom instruction and real world practice situations students will encounter in a realistic professional environment. The package also includes a number of other tools: numerous visual aids including buckling animations, slide shows, a 3-D building model with preset views for all connections, lab spreadsheets linked to the AISC Shapes Database for easy modification, web-based quizzes, project summary, editing instructions, a sample syllabus, and general building information. The entire package may be obtained from AISC by visiting their website: www.aisc.edu, see Figure 1. Our approach is different than the intended approach, which is detailed in the sample syllabus. We incorporate the entire package in the five-course sequence in structural engineering rather than one course.

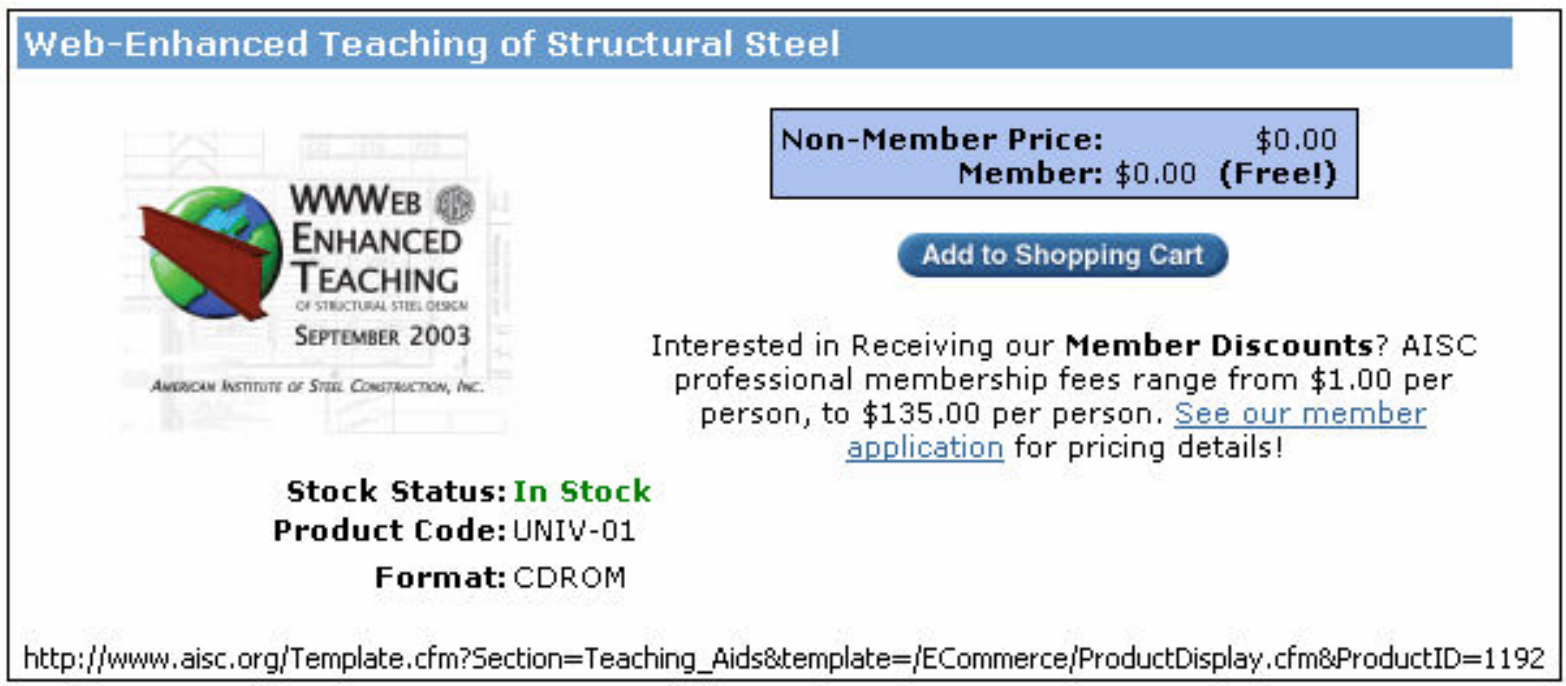

Figure 1: Web-Enhanced Teaching of Structural Steel Web Information.

\section{Implementation in the Structural Engineering Curriculum}

The structural engineering sequence at Texas A\&M University-Kingsville includes the following courses: 
statics $\rightarrow$ mechanics of materials $\rightarrow$ structural analysis $\rightarrow$ structural steel design $\rightarrow$ senior design There are several other course in structural engineering that are selected as electives and reinforced concrete, which is required, but is not included in the sequence discussed in this paper because the tools do not include any relevant material that can be used in the course.

\section{Statics}

This course is required for all students in architectural, civil, and mechanical engineering. The most relevant topic included in the Web-Enhanced Teaching of Structural Steel is loads. The textbook used for the class does not discuss the source of forces, which are typically represented with "arrows". Prior to the introduction of loads in the class using the "Where Do Loads Come From?" animation (which can be played using Windows Media Player, see Figure 2) students complained that they could not see how some of those forces were generated. Since the introduction of the topic in the class using the animation, the comments in the end of semester student evaluations have been very positive, particularly complementing the used of the animations. The AISC Steel Building Case Study is also introduced in the course to discuss the location of different structural elements within a building. Regarding assessment of the student's performance as a result of coverage of this material, no significant improvement in the grades has been noticed. This may be because the material does not directly impact the majority of the content of this particular course.

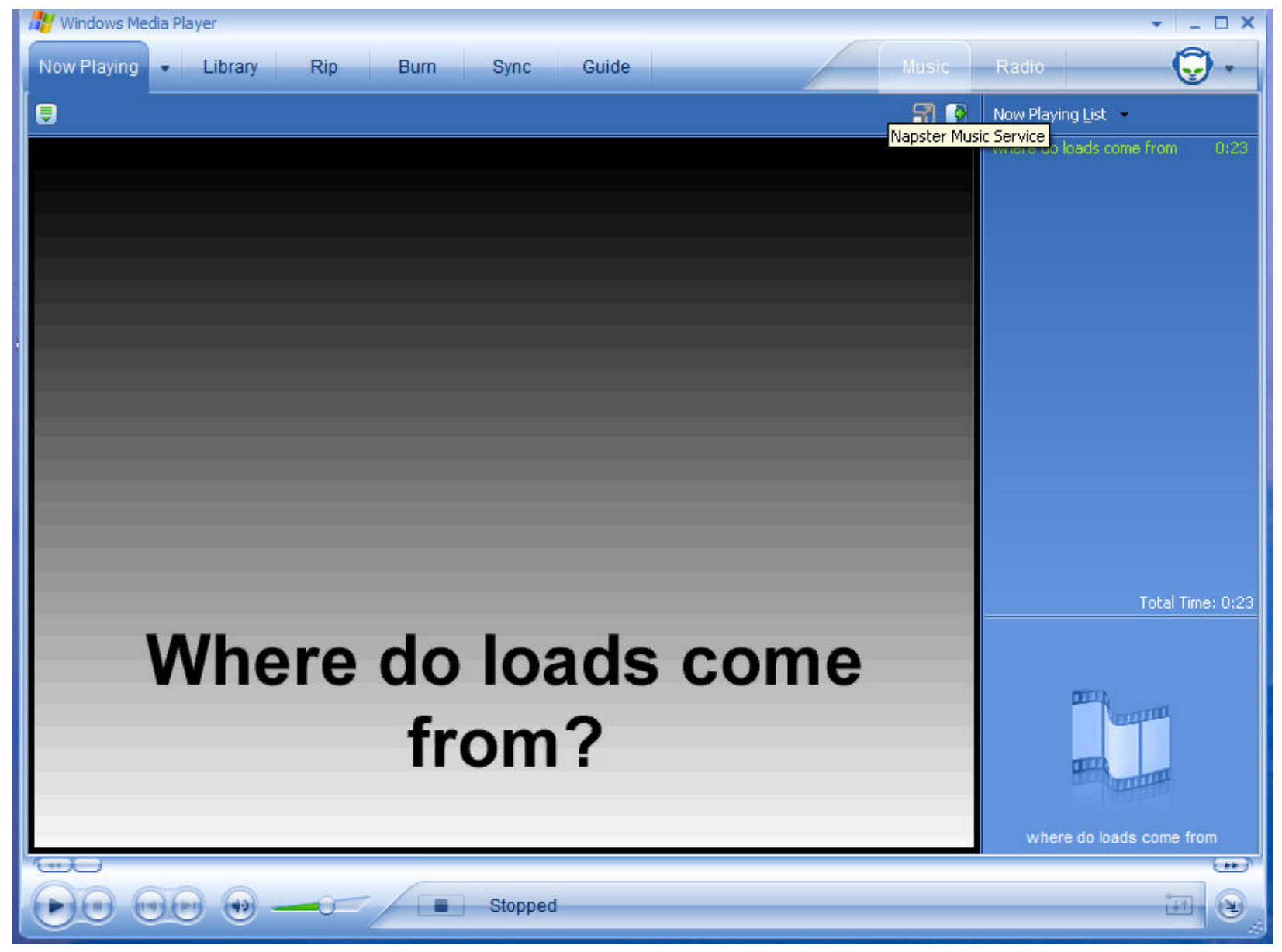

Figure 2: "Where Do Loads Come From?" animation. 


\section{Mechanics of Materials}

This course is also required for all students in architectural, civil, and mechanical engineering. In this course, we primarily concentrate on the aids covering failure modes for connections, deformations of members, and column buckling. The animations covering column bucking are particularly effective. The AISC Steel Building Case Study is also discussed in this course to introduce the concept of static indeterminacy. Again, since the introduction of these topics in the class using the animations, the comments in the end of semester student evaluations have been very positive. Regarding assessment of the student's performance as a result of coverage of this material, no significant improvement in the grades has been noticed. Again, this may be because the material does not impact the majority of the content of this particular course.

\section{Structural Analysis}

This course is required for students in architectural and civil engineering only. In this course, we discuss loads in detail and use some of the spreadsheets included in the tools as course assignments, specifically those used to compute loads (see homework assignment in Figure 3). One of the animations has been particularly effective in conveying the concept of tributary area and load path. Building construction is discussed using some of the site visit photo shows (including columns, beams, joists, and base plates), which are included in the package. In terms of analysis, students are required to perform approximate analyses of the frames. The package includes detail calculations of loads determined based on code requirements. In this course we introduce the students to graphical documentation of structural systems. Again, since the introduction of these topics in the class, the comments in the end of semester student evaluations have been very positive. Regarding assessment of the student's performance as a result of coverage of this material, understanding and calculation of loads has improved. The overall student understanding of how buildings are assembled and the purpose of structural analysis has also shown improvement. No other areas experienced significant improvement.

Due February 3, 2006

\section{CEEN 3303 - HWK \#2}

1. Solve problem 1-11 using hand calculations and the computer program in the downloads section of this web page.

2. Solve problems 1-14 and 1-16 using the wind load computer program.

3. Determine the wind load on the three story (plus a penthouse) office building given in the following architectural drawings $\underline{A}-1, \underline{A}-2, \underline{A}-3$, and $\underline{A}-4$. The wind direction is from west to east. Note that the building is located in Kansas (and as we all know, Kansas is flat as a pancake). Report the summary of your calculations on the following load sheet, $\underline{\mathrm{S}-8}$, and also estimate what the side pressure will be for the south and north sides of the building. To help you see the overall shape of the building, play with the following 3-D model of the building. You might need "Cosmo Player" in order to view the 3-D Model

Figure 3: Homework assignment based on the building case study. 


\section{Structural Steel Design}

In this course, we discuss building structural systems in detail, including 3-D systems (see Figure 4). Several of the animations help in conveying particularly difficult concepts such as block shear and local buckling. Structural steel building construction is discussed using some of the site visit photo shows, particularly to introduce the chapters where design of structural elements is covered. The structural drawings are discussed in class to introduce graphical documentation of designs. Several member designs (tension members, beams, and columns) are based on the calculation spreadsheets included in the package. We have also used the spreadsheets for homework assignments. Students first design a particular member from the case study by hand; then are given the spreadsheet to check their results and to design a similar member not part of the building case study. For this last part, the students must modify the spreadsheet to do the calculations, which reinforces the hand calculations and allows them to develop computer tools for design. The response of the students in this class has been particularly positive because students feel that the exercises are part of a "real structural building".

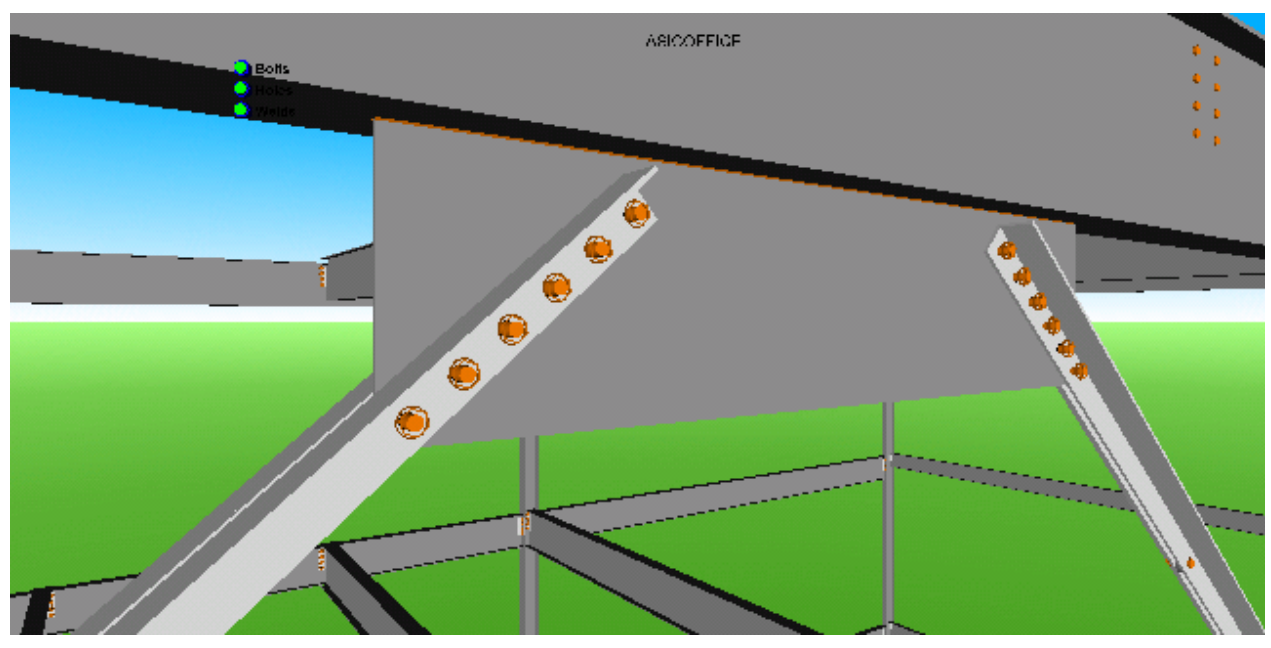

Figure 4: 3-D view a connection.

\section{Senior Design}

For the capstone senior design course, the building structural system is one of the projects assigned. The students start with the architectural drawings and select a structural system for the building. The tools include blank spreadsheets for the calculation of loads and design of members (see Figure 5). The students can modify these spreadsheets to form the calculations for the building structural system they have selected. This approach is similar to the approach intended for the toolkit.

\section{Conclusions and Recommendations}

The material presented in this paper is expected to give educators teaching structural engineering courses in both civil and architectural engineering programs an idea of how the Web-Enhanced Teaching of Structural Steel Design toolkit can be used to present difficult concepts and to bridge the gap between instruction and practice. 
It is recommended that instructors who wish to adopt this tool do so in steps. It is difficult to implement the entire project in a structural curriculum in one semester. Also, it is easier if the person trying to implement these ideas has taught all the courses in the sequence, but it is not necessary. We started by introducing the animations in statics and mechanics of materials. Then, We worked up to covering some of the spreadsheets and assigning analysis problems related to the building frame in structural analysis. Structural steel design assignments using the building elements were given last before taking the entire building and assigning it as a project in the senior design course. This was done over a period of about two to three years.

\begin{tabular}{|c|c|c|}
\hline Instructions & Blank Files: & Solution Files: \\
\hline \multicolumn{3}{|l|}{ Architectural Drawings: } \\
\hline A-1 - First Floor & & Acrobat (pdf) / AutoCAD (dwg) \\
\hline A-2 - Second and Third Floor Plan & & Acrobat (pdf) / AutoCAD (dwg) \\
\hline A-3 - Roof Plan & & Acrobat (pdf) / AutoCAD (.dwg) \\
\hline A-4 - Details & & $\overline{A c r o b a t}($ pdf) $/$ AutoCAD (.dwg) \\
\hline A-5 - Elevations & & Acrobat (pdf) / AutoCAD (dwg) \\
\hline \multicolumn{3}{|l|}{ Structural Drawings: } \\
\hline S-7 - N-S and E-W Section & Acrobat (.pdf) / AutoCAD (.dwg) & Acrobat (pdf) / AutoCAD (dwg) \\
\hline S-8 - Wind Loading & Acrobat (pdf) / AutoCAD (dwg) & Acrobat (pdf) / AutoCAD (.dwg) \\
\hline \multicolumn{3}{|l|}{ Spreadsheets: } \\
\hline AISC 01 - General Information & & Acrobat (pdf) / Excel (x|s) \\
\hline AISC 02 - Column Load Take off & Acrobat (.pdf) / Excel (xls) & Acrobat (pdf) / Excel (xls) \\
\hline AISC 03 - Vertical Loads & Acrobat (pdf) / Excel (x|s) & Acrobat (pdf) / Excel (xls) \\
\hline AISC 04 - Deck Selection & Acrobat (.pdf) / Excel (x|s) & Acrobat (pdf) / Excel (xls) \\
\hline AISC 05 - Rain Load & Acrobat (pdf) / Excel (x|s) & Acrobat (pdf) / Excel (x/s) \\
\hline AISC 06 - Wind Load & Acrobat (pdf) / Excel (xls) & Acrobat (pdf) / Excel $(x \mid s)$ \\
\hline AISC 07 - Snow Load & Acrobat (pdf) / Excel $(x \mid s)$ & Acrobat (pdf) / Excel $(x \mid s)$ \\
\hline \multicolumn{3}{|l|}{ Lab 2 - Loads: Seismic } \\
\hline Instructions & Blank Files: & Solution Files: \\
\hline \multicolumn{3}{|l|}{ Structural Drawings: } \\
\hline $\begin{array}{l}\text { S-9 - Rain, Snow, and Seismic Load } \\
\text { Diagrams }\end{array}$ & Acrobat (pdf) / AutoCAD (dwg) & Acrobat (pdf) / AutoCAD (dwg) \\
\hline \multicolumn{3}{|l|}{ Spreadsheets: } \\
\hline AISC 08 - Earthquake Loads & Acrobat (pdf) / Excel (x|s) & Acrobat (pdf) / Excel (x|s) \\
\hline
\end{tabular}

Figure 5: List of sample files included in the AISC Steel Building Case Study.

\section{Bibliography}

Barnes, C. (2004). Course Curriculum and Content for the Basic Structural Engineer: Survey Results. Structure Magazine, National Council of Structural Engineers Associations, July 2004, Pages 41-43.

Estrada, H. (2006). A Survey of the American Architectural Engineering Curriculum. Proceedings of 2006 ASEE Annual Conference and Exposition, Chicago, IL.

Roddis, W. M. K. (2006). Web-Enhanced Teaching of Steel Design: From Case Study to CD. Proceeding of the 2006 Structures Congress, ASCE.

Russell, J. S. and W. B. Stouffer (2005). Survey of the National Civil Engineering Curriculum. Journal of Professional Issues in Engineering Education and Practice, Vol. 131, No 2, April 1, 2005, Pages 118 - 128. 